\title{
openheart Does elevated bilirubin aid weight control by preventing development of hypothalamic leptin resistance?
}

\author{
James J DiNicolantonio, ${ }^{\oplus 1}$ Mark McCarty, ${ }^{2}$ James OKeefe ${ }^{๑ 1}$
}

To cite: DiNicolantonio JJ, McCarty M, OKeefe J. Does elevated bilirubin aid weight control by preventing development of hypothalamic leptin resistance?. Open Heart 2019;6:e000897. doi:10.1136/ openhrt-2018-000897

Accepted 4 March 2019
Check for updates

(C) Author(s) (or their employer(s)) 2019. Re-use permitted under CC BY-NC. No commercial re-use. See rights and permissions. Published by BMJ.

${ }^{1}$ Preventive Cardiology, Mid America Heart Institute, Kansas City, Missouri, USA

${ }^{2}$ Catalytic Longevity, Encinitas, California, USA

\section{Correspondence to} Dr James J DiNicolantonio; jjdinicol@gmail.com

\section{GILBERT SYNDROME IS ASSOCIATED WITH} LOWER GAIN IN FAT MASS DURING LATER LIFE

Gilbert syndrome (GS) is characterised by a lifelong genetically determined elevation of plasma unconjugated bilirubin levels. ${ }^{1}$ This typically entails decreased hepatic expression of the enzyme that conjugates free bilirubin to glucuronic acid, uridine-diphosphoglucuronate glucuronosyltransferase 1A1 (UGT1A1); this decreased activity reflects homozygosity for variant alleles in which promoter mutations decrease but do not eliminate transcription. In addition, genetic upregulation of bilirubin production-reflecting upregulation of haem oxygenase activity or increased haem synthesis-also contributes to the elevation of unconjugated bilirubin observed in subjects with GS. ${ }^{1-3}$ Diagnosis of GS generally requires a plasma bilirubin of $20 \mu \mathrm{M}$ or above-alternatively, $1.2 \mathrm{mg} / \mathrm{dL}$ - but this diagnosis is not entirely objective, as non-genetic factors such as fasting status, gastrointestinal motility, enterohepatic bilirubin reabsorption/secretion and degree of light exposure can cause bilirubin levels to vary considerably over time. Moreover, many individuals carrying genetic variants which decrease hepatic UGT1A1 activity maintain plasma bilirubin levels below the cut-off limits for GS diagnosis; these variants alone are not sufficient to guarantee a GS diagnosis. In any case, the key point to recognise is that tissues of properly diagnosed subjects with GS are exposed to quite significantly elevated unconjugated bilirubin levels over the course of their lives.

A recent cross-sectional epidemiological study evaluating subjects with GS has achieved some remarkable findings. ${ }^{4}$ This study enrolled 124 subjects with GS (average plasma unconjugated bilirubin $30.7 \mu \mathrm{M}$ ) and 124 age-matched and gender-matched controls $(8.7 \mu \mathrm{M})$. This study was unique in that it segregated the groups by age; subjects under and over age 35 were analysed separately. One of the most striking findings was this: whereas among the subjects under 35 body mass index (BMI) was only slightly but significantly lower in the GS group (22.5 vs 23.5, $\mathrm{p}<0.05)$, among those over 35 there was a large disparity: 23.8 vs $27.2(\mathrm{p}<0.001)$. The difference in body fat content in the over-35 group was even more stark: $21.8 \%$ in the subjects with GS vs $29.3 \%$ in the controls $(p<0.01)$. These findings suggest that elevated unconjugated bilirubin-and/ or possibly genetic upregulation of haem oxygenase activity-somehow prevents gain of body fat during ageing.

A recent study of diet-induced obesity in rats provides some confirmation of this idea. ${ }^{5}$ Rats fed a diet high in fats and sugar were injected intraperitoneally with bilirubin or vehicle for 14 days. Bilirubin treatment prevented a deterioration in glucose tolerance and suppressed weight gain. In addition, compared with control mice, bilirubin-treated mice had reductions in total cholesterol and leptin and increases in adiponectin. A trend towards decreased calorie consumption in the bilirubin-treated rats also nearly achieved statistical significance $(\mathrm{p}=0.06)$.

Gunn rats, like humans with GS, are characterised by a genetically determined deficit of hepatic UGT1A1 activity and a lifelong elevation of unconjugated plasma bilirubin. ${ }^{6}$ It therefore is pertinent to note that aged Gunn rats are characterised by a lower level of visceral fat than is seen in littermates with normal hepatic UGT1A1 activity. ${ }^{7}$ Moreover, these rats enjoy better glucose tolerance, reduced oxidative stress and decreased serum levels of proinflammatory cytokines, suggesting that metabolic syndrome and systemic inflammation are ameliorated in such rats. 
UNCONJUGATED BILIRUBIN FUNCTIONS PHYSIOLOGICALLY TO INHIBIT NADPH OXIDASE COMPLEXES

Physiological intracellular levels of unconjugated bilirubin have been shown to inhibit certain common isoforms of NADPH oxidase. ${ }^{8-12}$ This phenomenon likely explains the profound antioxidant activity of haem oxygenase, which cleaves haem to yield biliverdin, carbon monoxide and free iron; biliverdin is then rapidly reduced by the ubiquitously expressed enzyme biliverdin reductase to yield bilirubin. Expression of inducible form of haem oxygenase, HO-1, can be boosted by oxidative stress-often derived from NADPH oxidase activity; the resultant production of bilirubin feeds back to quell this oxidative stress. ${ }^{11}$ Although bilirubin can also act as a direct oxidant scavenger, its physiological intracellular level-in the low nanomolar range-is too low to compete in this regard with other intracellular scavengers (eg, glutathione, ascorbate) present in millimolar concentrations. $^{13}$

Oxidative stress in adipocytes, stemming largely from NADPH oxidase activity, appears to play a key role in the induction of insulin resistance and the skewing of adipokine and cytokine production in hypertrophied adipocytes. ${ }^{14-19}$ Hence, bilirubin and haem oxygenase activity could be expected to aid maintenance of adipocyte insulin sensitivity. Indeed, plasma levels of unconjugated bilirubin have been found to correlate inversely with risk for metabolic syndrome and diabetes in prospective epidemiological studies, as confirmed in a recent meta-analysis. $^{20}$ However, insulin induces uptake and retention of fatty acids by adipocytes; hence, bilirubin's presumed ability to aid maintenance of adipocyte insulin sensitivity would be expected to boost body fat content, not decrease it. Hence, we need to look elsewhere for an explanation of the decreased risk for body fat gain in subjects with GS.

\section{MICROGLIAL ACTIVATION AS A MEDIATOR OF HYPOTHALAMIC LEPTIN RESISTANCE: A TARGET FOR BILIRUBIN?}

One of the phenomena that promote weight gain as people grow older is the development of hypothalamic leptin resistance. ${ }^{21}$ The hormone leptin is produced primarily in adipocytes, and its plasma levels rise as body fat mass increases. Leptin functions to counteract inappropriate weight gain by acting on leptin-responsive neurons in the hypothalamus to suppress appetite while also boosting metabolic rate via sympathetic activation. $^{22-24}$ Of particular interest in this regard are leptin-responsive neurons in the arcuate nucleus of the mediobasal hypothalamus $(\mathrm{MBH})$; the $\mathrm{MBH}$ has a poorly developed blood-brain barrier, and hence hormones, free fatty acids and other plasma components have ready access to it. ${ }^{25}$ Leptin-responsive neurons in the arcuate nucleus boost anorexic signalling by increasing neuronal release of pro-opiomelanocortin, while suppressing release of the orexigenic hormones neuropeptide $\mathrm{Y}$ and agouti-related peptide within this nucleus. The physiological importance of this mechanism, at least in mice, is confirmed by the fact that genetic strains of mice which are incapable of making either leptin (ob/ob) or functional leptin receptors $(\mathrm{db} / \mathrm{db})$ overeat and become obese and diabetic. ${ }^{2627}$

Unfortunately, efforts to develop injectable leptin as an antiobesity drug have not been successful, as overweight subjects are resistant to its suppressive impact on appetite. Studies in rodents with diet-induced obesity suggest that this phenomenon reflects a loss of leptin responsiveness that is specific to the arcuate nucleus. ${ }^{21}$ 28-30 Activated leptin receptors trigger JAK2-mediated phosphorylation of STAT3, which then migrates as a homodimer to the nucleus to modulate gene transcription. In lean chow-fed rodents, a leptin injection rapidly boosts pSTAT3 levels in the arcuate nucleus and suppresses feeding; this response is substantially blunted in obese rodents. In contrast, leptin is able to raise pSTAT3 levels in other leptin-responsive regions of the brain in obese rodents. ${ }^{31}$

Although the molecular biology underlying hypothalamic leptin resistance in obesity is still somewhat obscure, studies focusing on high-fat/high-sugar diet-induced obesity in rodents have yielded some intriguing findings. In particular, activation and proliferation of microglia in the $\mathrm{MBH}$ are noted in rodents with diet-induced obesity. ${ }^{32-34}$ The microglial activation noted in this situation appears to be mediated primarily by saturated fatty acids interacting with toll-like receptor-4 (TLR4) expressed by microglia. ${ }^{32} 3536$ (Plasma-derived fetuin-A forms a trimeric complex with fatty acids and TLR4, catalysing this interaction. ${ }^{37-39}$ ) Hence, TLR4 antagonistsbut not TLR2 antagonists-prevent microglial activation and development of leptin resistance in rats fed a fatty diet. ${ }^{35}$ Microglial proliferation is also noted in this circumstance, and measures which prevent microglial proliferation have likewise been found to prevent development of leptin resistance in rodents. ${ }^{32} 33$ How activated microglia act to impair leptin responsiveness in the arcuate nucleus is still unclear.

A key role for saturated fatty acids in driving leptin resistance might help to explain why risk for obesity is lower in those who habitually consume plant-based or 'Mediterranean' diets in which saturated fats constitute a relatively low percentage of total fatty acids. ${ }^{40-47}$ Risk for type 2 diabetes has been found to be markedly lower in individuals who follow a plant-based diet. ${ }^{48}$ Increased hepatic production of fibroblast growth factor 21 may also contribute to the obesity prevention associated with plant-based diets of modest protein content. ${ }^{49-51}$

Activation of microglia via TLR4-as with lipopolysaccharides-has been shown to entail activation of Nox2-dependent NADPH oxidase. ${ }^{52-54}$ Moreover, this activation is required for production of toxic oxidants such as peroxynitrite, and increased production of proinflammatory cytokines and prostanoids. Hence, it is straightforward to propose that bilirubin may have the ability to downregulate microglial activation by diminishing NADPH oxidase activation. ${ }^{55}$ In light of the 
foregoing discussion, a corollary of this is that elevated bilirubin-whether derived from plasma or from local haem oxygenase activity-may oppose the evolution of leptin resistance by inhibiting the activation (and likely proliferation) of microglia in the MBH. The ability of the HO-1 inducer haemin to alleviate hyperleptinaemia- a marker for leptin resistance-in fat-fed rats appears consistent with this possibility. ${ }^{56}$

With respect to bilirubin and microglia, it should be noted that, when unconjugated bilirubin exceeds its solubility limit (70 nM), it can disrupt membranes and promote microglial activation. ${ }^{57}$ This explains the neural damage and microglial activation associated with perinatal bilirubin encephalopathy, which can occur in newborns whose livers have limited capacity to conjugate bilirubin at a time when the blood-brain barrier is poorly formed. Analogously, bilirubin neurotoxicity is seen in Crigler-Najjar syndrome, in which mutations of the UGT1A1 render it non-functional, and plasma bilirubin levels are roughly an order of magnitude higher than those seen in GS. ${ }^{59}$ The concentrations of unconjugated bilirubin which result from haem oxygenase induction appear to be below its solubility limit, as such induction tends to suppress microglial activation and provide neuroprotection in rodent or cell culture models. ${ }^{60}$ In endothelial cells, bilirubin's antioxidant activity has been found to be half-maximal at $11 \mathrm{nM}$; hence, bilirubin can function physiologically as an important intracellular antioxidant in concentrations far below its solubility limit.

One of the cytokines whose expression by microglia is contingent on Nox2 activity is tumour necrosis factoralpha $(\mathrm{TNF} \alpha){ }^{52}{ }^{53} \mathrm{TNF} \alpha$, via Nuclear factor-kappa beta (NF-kappaB) activation, provokes increased hypothalamic expression of phosphotyrosine phosphatase-1A (PTP1B), which functions as an antagonist of leptin signalling by reversing activating tyrosine phosphorylation of JAK2. ${ }^{61-64}$ Hypothalamic PTP1B activity increases in response to high-fat diets in rodents, and neuronal PTP1B knockout mice fail to develop leptin resistance and obesity when fed such diets; a similar effect is seen when hypothalamic PTP1B activity is inhibited with antisense oligonucleotides. ${ }^{616566}$ Hence, the TNF $\alpha$ produced by microglia-and possibly other cytokines capable of inducing PTP1B in neurons-likely contributes to leptin resistance by boosting PTP1B expression.

Additionally, there is evidence that hypothalamic TNF $\alpha$ can oppose leptin resistance by additional mechanisms, likely including increased expression of suppressor of cytokine signalling-3 (SOCS-3) ${ }^{62}$ This protein, via an inhibitory interaction with JAK2, blocks all known signalling pathways activated by the leptin receptor. It is elevated in the hypothalamus of fat-fed rodents, and mice that are heterozygous for SOCS-3 gene deletion are resistant to diet-induced obesity. ${ }^{6768}$ SOCS-3 is induced at the transcriptional level by leptin, and thus provides feedback regulation of leptin activity. ${ }^{69} \mathrm{TNF} \alpha$ can increase its expression by boosting the half-life of its mRNA, thereby amplifying the efficacy of this negative feedback mechanism..$^{70}$ In obese mice whose leptin is clamped at a lower level similar to that of lean mice, an injection of leptin causes a normal rise in arcuate pSTAT3; this might reflect the fact that their baseline level of SOCS-3 in leptin-responsive arcuate neurons is relatively low. ${ }^{71}$

If we presume, not unreasonably, that hypothalamic leptin resistance tends to evolve and worsen gradually over a lifetime-possibly reflecting proliferation of activated microglia in the arcuate nucleus-then the fact that body composition is only slightly modified in young subjects with GS relative to controls may simply reflect the fact that bilirubin cannot influence leptin activity until leptin resistance begins to develop.

\section{BILIRUBIN-MIMETIC STRATEGIES FOR OBESITY PREVENTION}

These considerations may be of more than just theoretical interest. Although bilirubin is too insoluble to be useful as a nutraceutical, and its precursor biliverdin is quite expensive to synthesise, the biliverdin derivative and homologue phycocyanobilin (PhyCB) is a prominent light-harvesting chromophore in many cyanobacteria and blue-green algae. Spirulina, a cyanobacterium traditionally used as a food in certain cultures, can contain about $0.6 \%$ PhyCB by dry weight. ${ }^{72}$ This likely explains why oral administration of spirulina-or of phycocyanin, the blue algal protein which carries PhyCB as a covalently attached chromophore-has been found to exert profound antioxidant and anti-inflammatory effects in rodent models of a wide range of health disorders. ${ }^{72-74}$ Protective effects of oral spirulina in rodent models of neurodegeneration may indeed reflect, in part, diminished activation of microglia; in particular, spirulina is effective in rodent models of Parkinson's disease, in which activated microglia are suspected to play a key role in the destruction of dopaminergic neurons. ${ }^{55}$ 75-78 Although intakes of spirulina sufficiently high to exert important antioxidant activity are difficult to achieve in humans owing to the undesirable flavour and especially odour of spirulina, the development of PhyCB-enriched spirulina extracts suitable for nutraceutical use may make it far easier to achieve the benefits of PhyCB clinically. ${ }^{72}$

It may be noted that, in one of the very few controlled clinical studies in which ample doses of spirulina were administered-protease inhibitor-treated patients with HIV preselected for insulin resistance received $19 \mathrm{~g}$ daily of spirulina or soy protein-insulin sensitivity in the spirulina-treated subjects, assessed by a short intravenous insulin tolerance test, roughly tripled. ${ }^{79}$ (The study was however marred by a high dropout rate in the spirulina group, as many of the subjects could not tolerate spirulina's flavour.)

Alternatively, it may prove feasible to induce an 'iatrogenic Gilbert syndrome' by administering drugs or nutraceuticals that inhibit UGT1A1 activity. ${ }^{1380}$

If the hypothesis presented here is correct, the far lower body fat in older subjects with GS reflects the ability of bilirubin to suppress the activation and proliferation of 
microglia in the MBH. The extent to which this expansion of activated microglia—and the associated impact on the function of leptin-responsive neurons-can be reversed by elevation of bilirubin (or administration of PhyCB) in patients who have already developed obesity with leptin resistance remains to be seen. Particularly because microglial mass increases, it may be rash to assume that this syndrome is fully reversible. ${ }^{81}$ If PhyCB does prove to have utility for controlling hypothalamic inflammation, its greatest impact on obesity will likely be achieved by long-term administration in a preventive mode.

In any case, studies evaluating the impact of bilirubin or PhyCB administration on the development of hypothalamic leptin resistance in fat-fed rodents appear to be warranted. These studies could assess whether leptin's ability to amplify pSTAT3 levels in the arcuate nucleus of fat-fed rats-while suppressing feeding-is boosted by concurrent administration of bilirubin or PhyCB.

Two studies have been published very recently in which inclusion of spirulina in the diet has been shown to inhibit gain in body weight and fat in rats fed a high-fat diet; these appear to be the first studies to have evaluated spirulina's impact in this regard. ${ }^{82} 83$ Although neither of these studies focused on leptin function, the fact that markers of adipose tissue browning were higher in rats receiving spirulina is consistent with effective leptin function in these rats. Moreover, a double-blind, placebo-controlled clinical trial has also emerged, in which spirulina supplementation (at only $2 \mathrm{~g}$ daily) was found to potentiate loss of body fat, body weight, waist circumference and BMI in overweight subjects placed on a calorie-restricted diet; reductions in triglycerides and $\mathrm{C}$ reactive protein were also greater in the spirulina group. ${ }^{84}$

\section{PRESERVING AND UPREGULATING HYPOTHALAMIC LEPTIN SIGNALLING AS A STRATEGY FOR METABOLIC HEALTH}

Bilirubin mimesis may represent one example of a more general strategy for preventing or reversing inappropriate weight gain: counteracting hypothalamic leptin resistance or upregulating hypothalamic leptin signalling. ${ }^{59} 85$

For example, histamine, acting via $\mathrm{H} 1$ receptors, functions as a downstream mediator of hypothalamic leptin signalling, and this signalling can be upregulated by histidine supplementation. ${ }^{86} 87$ Rodent studies indicate that an increase in dietary histidine can increase hypothalamic histamine levels, boost hypothalamic expression of histidine decarboxylase, inhibit food intake, increase sympathetic activity in fat tissue and decrease the size of the retroperitoneal fat pad ${ }^{88-91}$ In rats fed a high-fat diet, an increase in dietary histidine attenuated weight gain and decreased markers for inflammation in adipose tissue. ${ }^{92}$ In a controlled clinical trial, overweight women with metabolic syndrome were supplemented with $4 \mathrm{~g}$ histidine daily or matching placebo for 12 weeks; the group receiving histidine lost $2.7 \mathrm{~kg}$ of body fat and achieved improvements in insulin sensitivity and other parameters related to metabolic syndrome, changes that were significant relative to negligible changes in the placebo group. ${ }^{93}$ Moreover, cross-sectional epidemiology has correlated increased dietary intake of histidine (absolutely or as a fraction of total protein) with lower daily calorie intake and decreased BMI and waist circumference. ${ }^{94}{ }^{95}$ Conversely, chronic use of prescription H1-antagonist antihistamines has been linked to increased risk for obesity ${ }^{96}$ Hence, histidine supplementation may emerge as an additional strategy for aiding weight control by optimising leptin signalling. ${ }^{97}$

Maintaining effective androgen activity may support hypothalamic leptin signalling in men. The activated androgen receptor in neurons functions to suppress NF-kappaB-mediated induction of PTP1B. ${ }^{98}$ Hence, hypothalamic androgen activity may blunt the ability of activated microglia to induce leptin resistance. Reduction of testosterone levels associated with ageing (andropause), as well as androgen deprivation therapy in patients with prostate cancer, are known to increase the risk of weight gain and metabolic syndrome; conversely, restoration of youthful testosterone levels in ageing men has been found to be protective in these respects. $^{99-103}$

Additional potential strategies for boosting hypothalamic leptin signalling have been proposed. Orally available selective inhibitors of PTP1B may have potential as pharmaceuticals for restoring leptin responsiveness. ${ }^{104} 105$ In this regard, cinnamon, which contains a compound that can inhibit the rat homologue of PTP1B, has been shown to inhibit gain of body fat in rats fed a high-fat/high-fructose diet, and also has been found to reduce the BMI of women with polycystic ovary syndrome in a recent controlled study. ${ }^{106-108}$

Contributors All authors contributed to the final manuscript.

Funding The authors have not declared a specific grant for this research from any funding agency in the public, commercial or not-for-profit sectors.

Competing interests JJD is the author of The Salt Fix, Superfuel and The Longevity Solution. MM is an owner of a nutraceutical company and coinventor and co-owner of a US patent covering nutraceutical uses of phycocyanobilin oligopeptides derived from cyanobacteria such as spirulina. J0 is an owner of a nutraceutical company.

Patient consent for publication Not required.

Provenance and peer review Not commissioned; externally peer reviewed.

Open access This is an open access article distributed in accordance with the Creative Commons Attribution Non Commercial (CC BY-NC 4.0) license, which permits others to distribute, remix, adapt, build upon this work non-commercially, and license their derivative works on different terms, provided the original work is properly cited, appropriate credit is given, any changes made indicated, and the use is non-commercial. See: http://creativecommons.org/licenses/by-nc/4.0/.

\section{REFERENCES}

1. Kadakol A, Ghosh SS, Sappal BS, et al. Genetic lesions of bilirubin uridine-diphosphoglucuronate glucuronosyltransferase (UGT1A1) causing Crigler-Najjar and gilbert syndromes: correlation of genotype to phenotype. Hum Mutat 2000;16:297-306.

2. McCarty MF. Serum bilirubin may serve as a marker for increased heme oxygenase activity and inducibility in tissues - a rationale for the versatile health protection associated with elevated plasma bilirubin. Med Hypotheses 2013;81:607-10. 
3. Wallner M, Bulmer AC, Mölzer C, et al. Haem catabolism: a novel modulator of inflammation in Gilbert's syndrome. Eur J Clin Invest 2013;43:912-9.

4. Seyed Khoei N, Grindel A, Wallner M, et al. Mild hyperbilirubinaemia as an endogenous mitigator of overweight and obesity: implications for improved metabolic health. Atherosclerosis 2018;269:306-11.

5. Liu J, Dong $\mathrm{H}$, Zhang $\mathrm{Y}$, et al. Bilirubin increases insulin sensitivity by regulating cholesterol metabolism, adipokines and PPAR $\gamma$ levels. Sci Rep 2015;5.

6. Chowdhury JR, Kondapalli R, Chowdhury NR. Gunn rat: a model for inherited deficiency of bilirubin glucuronidation. Adv Vet Sci Comp Med 1993;37:149-73.

7. Zelenka J, Dvořák A, Alán L, et al. Hyperbilirubinemia protects against aging-associated inflammation and metabolic deterioration. Oxid Med Cell Longev 2016;2016:1-10.

8. Lanone S, Bloc S, Foresti R, et al. Bilirubin decreases nos2 expression via inhibition of $\mathrm{NAD}(\mathrm{P}) \mathrm{H}$ oxidase: implications for protection against endotoxic shock in rats. FASEB $J$ 2005;19:1890-2.

9. Matsumoto $\mathrm{H}$, Ishikawa $\mathrm{K}$, Itabe $\mathrm{H}$, et al. Carbon monoxide and bilirubin from heme oxygenase-1 suppresses reactive oxygen species generation and plasminogen activator inhibitor-1 induction. Mol Cell Biochem 2006;291:21-8.

10. Jiang F, Roberts SJ, Datla Sraju, et al. No modulates NADPH oxidase function via heme oxygenase-1 in human endothelial cells. Hypertension 2006;48:950-7.

11. Datla SR, Dusting GJ, Mori TA, et al. Induction of heme oxygenase-1 in vivo suppresses NADPH Oxidase-Derived oxidative stress. Hypertension 2007;50:636-42.

12. Basuroy S, Bhattacharya S, Leffler CW, et al. NOX4 NADPH oxidase mediates oxidative stress and apoptosis caused by TNF- $\alpha$ in cerebral vascular endothelial cells. Am J Physiol Cell Physiol 2009;296:C422-C432.

13. McCarty MF. "latrogenic Gilbert syndrome"- A strategy for reducing vascular and cancer risk by increasing plasma unconjugated bilirubin. Med Hypotheses 2007;69:974-94.

14. Talior I, Tennenbaum T, Kuroki T, et al. PKC- $\delta$-dependent activation of oxidative stress in adipocytes of obese and insulin-resistant mice: role for NADPH oxidase. Am J Physiol Endocrinol Metab 2005;288:E405-E411.

15. Furukawa S, Fujita T, Shimabukuro M, et al. Increased oxidative stress in obesity and its impact on metabolic syndrome. J Clin Invest 2004;114:1752-61.

16. Han CY, Umemoto T, Omer M, et al. NADPH oxidase-derived reactive oxygen species increases expression of monocyte chemotactic factor genes in cultured adipocytes. J Biol Chem 2012;287:10379-93.

17. Lin L, Pang W, Chen K, et al. Adipocyte expression of PU.1 transcription factor causes insulin resistance through upregulation of inflammatory cytokine gene expression and ROS production. Am $J$ Physiol Endocrinol Metab 2012;302:E1550-E1559.

18. Jankovic A, Korac A, Buzadzic B, et al. Redox implications in adipose tissue (dys)function-A new look at old acquaintances. Redox Biol 2015;6:19-32.

19. Prokudina ES, Maslov LN, Ivanov VV, et al. The role of reactive oxygen species in the pathogenesis of adipocyte dysfunction in metabolic syndrome. Prospects of pharmacological correction. Vestn Ross Akad Med Nauk 2017;72:11-16.

20. Nano J, Muka T, Cepeda M, et al. Association of circulating total bilirubin with the metabolic syndrome and type 2 diabetes: a systematic review and meta-analysis of observational evidence. Diabetes Metab 2016;42:389-97.

21. Carter S, Caron A, Richard D, et al. Role of leptin resistance in the development of obesity in older patients. Clin Interv Aging 2013;8:829-44.

22. Rahmouni K, Morgan DA. Hypothalamic arcuate nucleus mediates the sympathetic and arterial pressure responses to leptin. Hypertension 2007;49:647-52

23. Morrison CD. Leptin resistance and the response to positive energy balance. Physiol Behav 2008;94:660-3.

24. Williams KW, Scott MM, Elmquist JK. From observation to experimentation: leptin action in the mediobasal hypothalamus. Am J Clin Nutr 2009;89:985S-90.

25. Lam TKT, Schwartz GJ, Rossetti L. Hypothalamic sensing of fatty acids. Nat Neurosci 2005;8:579-84.

26. Pelleymounter M, Cullen M, Baker M, et al. Effects of the obese gene product on body weight regulation in ob/ob mice. Science 1995;269:540-3.

27. Chen $\mathrm{H}$, Charlat $\mathrm{O}$, Tartaglia LA, et al. Evidence that the Diabetes gene encodes the leptin receptor: identification of a mutation in the leptin receptor gene in db/db mice. Cell 1996;84:491-5.
28. Dong M, Ren J. What fans the fire: insights into mechanisms of leptin in metabolic syndrome-associated heart diseases. Curr Pharm Des 2014;20:652-8.

29. Jung $\mathrm{CH}$, Kim M-S. Molecular mechanisms of central leptin resistance in obesity. Arch. Pharm. Res. 2013;36:201-7.

30. Zhou Y, Rui L. Leptin signaling and leptin resistance. Front. Med. 2013;7:207-22.

31. Münzberg H, Flier JS, Bjørbæk C. Region-specific leptin resistance within the hypothalamus of diet-induced obese mice. Endocrinology 2004;145:4880-9.

32. Valdearcos M, Robblee MM, Benjamin DI, et al. Microglia dictate the impact of saturated fat consumption on hypothalamic inflammation and neuronal function. Cell Rep 2014;9:2124-38.

33. André C, Guzman-Quevedo O, Rey C, et al. Inhibiting microglia expansion prevents diet-induced hypothalamic and peripheral inflammation. Diabetes 2017;66:908-19.

34. Valdearcos M, Xu AW, Koliwad SK. Hypothalamic inflammation in the control of metabolic function. Annu Rev Physiol 2015;77:131-60.

35. Milanski M, Degasperi G, Coope A, et al. Saturated fatty acids produce an inflammatory response predominantly through the activation of TLR4 signaling in hypothalamus: implications for the pathogenesis of obesity. J Neurosci 2009;29:359-70.

36. Cheng L, Yu Y, Szabo A, et al. Palmitic acid induces central leptin resistance and impairs hepatic glucose and lipid metabolism in male mice. J Nutr Biochem 2015;26:541-8.

37. Pal D, Dasgupta S, Kundu R, et al. Fetuin-A acts as an endogenous ligand of TLR4 to promote lipid-induced insulin resistance. Nat Med 2012;18:1279-85

38. Trepanowski JF, Mey J, Varady KA. Fetuin-A: a novel link between obesity and related complications. Int J Obes 2015;39:734-41.

39. Mukhopadhyay S, Bhattacharya S. Plasma fetuin-A triggers inflammatory changes in macrophages and adipocytes by acting as an adaptor protein between NEFA and TLR-4. Diabetologia 2016;59:859-60.

40. Toohey ML, Harris MA, DeWitt W, et al. Cardiovascular disease risk factors are lower in African-American vegans compared to lactoovo-vegetarians. J Am Coll Nutr 1998;17:425-34.

41. Spencer EA, Appleby PN, Davey GK, et al. Diet and body mass index in 38000 EPIC-Oxford meat-eaters, fish-eaters, vegetarians and vegans. Int J Obes 2003;27:728-34.

42. Newby PK, Tucker KL, Wolk A. Risk of overweight and obesity among semivegetarian, lactovegetarian, and vegan women. Am J Clin Nutr 2005;81:1267-74.

43. Waldmann A, Koschizke JW, Leitzmann C, et al. German vegan study: diet, life-style factors, and cardiovascular risk profile. Ann Nutr Metab 2005;49:366-72.

44. Rosell M, Appleby P, Spencer E, et al. Weight gain over 5 years in 21966 meat-eating, fish-eating, vegetarian and vegan men and women in EPIC-Oxford. Int J Obes 2006;30:1389-96.

45. Panagiotakos DB, Chrysohoou C, Pitsavos C, et al. Association between the prevalence of obesity and adherence to the Mediterranean diet: the Attica study. Nutrition 2006;22:449-56.

46. Shubair MM, McColl RS, Hanning RM. Mediterranean dietary components and body mass index in adults: the peel nutrition and heart health survey. Chronic Dis Can 2005;26:43-51.

47. Schröder H, Marrugat J, Vila J, et al. Adherence to the traditional Mediterranean diet is inversely associated with body mass index and obesity in a Spanish population. J Nutr 2004:134:3355-61.

48. Tonstad S, Butler T, Yan R, et al. Type of vegetarian diet, body weight, and prevalence of type 2 diabetes. Diabetes Care 2009;32:791-6.

49. McCarty MF. The moderate essential amino acid restriction entailed by low-protein vegan diets may promote vascular health by stimulating FGF21 secretion. Horm Mol Biol Clin Investig 2016;30.

50. Fontana L, Cummings NE, Arriola Apelo SI, et al. Decreased consumption of branched-chain amino acids improves metabolic health. Cell Rep 2016;16:520-30.

51. Sonoda J, Chen MZ, Baruch A. FGF21-receptor agonists: an emerging therapeutic class for obesity-related diseases. Horm Mol Biol Clin Investig 2017;30.

52. Qin L, Liu Y, Wang T, et al. NADPH oxidase mediates lipopolysaccharide-induced neurotoxicity and proinflammatory gene expression in activated microglia. J. Biol. Chem. 2004:279:1415-21.

53. Qin L, Li G, Qian X, et al. Interactive role of the Toll-like receptor 4 and reactive oxygen species in LPS-induced microglia activation. Glia 2005;52:78-84.

54. Sorce S, Stocker R, Seredenina T, et al. NADPH oxidases as drug targets and biomarkers in neurodegenerative diseases: what is the evidence? Free Radic Biol Med 2017;112:387-96. 
55. McCarty MF, Barroso-Aranda J, Contreras F. Oral phycocyanobilin may diminish the pathogenicity of activated brain microglia in neurodegenerative disorders. Med Hypotheses 2010;74:601-5.

56. Szkudelski T, Dłużewicz K, Sadoch J, et al. Effects of the activation of heme oxygenase-1 on hormonal and metabolic changes in rats fed a high-fat diet. Biomed Pharmacother 2017;87:375-80.

57. Gordo AC, Falcão AS, Fernandes A, et al. Unconjugated bilirubin activates and damages microglia. J Neurosci Res 2006;84:194-201.

58. Silva SL, Vaz AR, Barateiro A, et al. Features of bilirubin-induced reactive microglia: from phagocytosis to inflammation. Neurobiol Dis 2010;40:663-75

59. Quarta C, Sánchez-Garrido MA, Tschöp MH, et al. Renaissance of leptin for obesity therapy. Diabetologia 2016;59:920-7.

60. Jazwa A, Cuadrado A. Targeting heme oxygenase-1 for neuroprotection and neuroinflammation in neurodegenerative diseases. Curr Drug Targets 2010;11:1517-31.

61. Zabolotny JM, Kim Y-B, Welsh LA, et al. Protein-tyrosine Phosphatase 1B Expression Is Induced by Inflammation in Vivo. J Biol Chem 2008;283:14230-41.

62. Picardi PK, Caricilli AM, de Abreu LLF, et al. RETRACTED: modulation of hypothalamic PTP1B in the TNF- $\alpha$-induced insulin and leptin resistance. FEBS Lett 2010;584:3179-84.

63. Ito $\mathrm{Y}, \mathrm{Banno} \mathrm{R}$, Hagimoto $\mathrm{S}$, et al. TNF $\alpha$ increases hypothalamic PTP1B activity via the NF $\kappa$ B pathway in rat hypothalamic organotypic cultures. Regul Pept 2012;174:58-64

64. Zabolotny JM, Bence-Hanulec KK, Stricker-Krongrad A, et al. PTP1B regulates leptin signal transduction in vivo. Dev Cell 2002;2:489-95

65. Picardi PK, Calegari VC, Prada PO, et al. Reduction of hypothalamic protein tyrosine phosphatase improves insulin and leptin resistance in diet-induced obese rats. Endocrinology 2008;149:3870-80.

66. White CL, Whittington A, Barnes MJ, et al. HF diets increase hypothalamic PTP1B and induce leptin resistance through both leptin-dependent and -independent mechanisms. Am J Physiol Endocrinol Metab 2009;296:E291-E299.

67. Mori $\mathrm{H}$, Hanada R, Hanada T, et al. SOCS3 deficiency in the brain elevates leptin sensitivity and confers resistance to diet-induced obesity. Nat Med 2004;10:739-43.

68. Howard JK, Cave BJ, Oksanen LJ, et al. Enhanced leptin sensitivity and attenuation of diet-induced obesity in mice with haploinsufficiency of SOCS3. Nat Med 2004;10:734-8.

69. Bjørbæk C, Elmquist JK, Frantz JD, et al. Identification of SOCS3 as a potential mediator of central leptin resistance. Mol Cell 1998;1:619-25.

70. Ehlting C, Lai WS, Schaper F, et al. Regulation of Suppressor of Cytokine Signaling 3 (SOCS3) mRNA Stability by TNF- Involves Activation of the MKK6/p38MAPK/MK2 Cascade. J Immunol 2007;178:2813-26.

71. Knight ZA, Hannan KS, Greenberg ML, et al. Hyperleptinemia is required for the development of leptin resistance. PLOS ONE 2010;5:e11376.

72. McCarty MF. Clinical Potential of Spirulina as a Source of Phycocyanobilin. J Med Food 2007;10:566-70.

73. Romay C, González R, Ledón N, et al. C-phycocyanin: a biliprotein with antioxidant, anti-inflammatory and neuroprotective effects. Curr Protein Pept Sci 2003;4:207-16.

74. Liu Q, Huang Y, Zhang R, et al. Medical application of Spirulina platensis derived C-phycocyanin. Evid Based Complement Alternat Med 2016;2016.

75. Chamorro G, Pérez-Albiter M, Serrano-García N, et al. Spirulina maxima pretreatment partially protects against 1-methyl-4phenyl-1,2,3,6-tetrahydropyridine neurotoxicity. Nutr Neurosci 2006;9:207-12

76. Pabon MM, Jernberg JN, Morganti J, et al. A Spirulina-Enhanced diet provides neuroprotection in an $\alpha$-synuclein model of Parkinson's disease. PLOS ONE 2012;7:e45256.

77. Tobón-Velasco JC, Palafox-Sánchez V, Mendieta L, et al. Antioxidant effect of Spirulina (Arthrospira) maxima in a neurotoxic model caused by $6-O H D A$ in the rat striatum. J Neural Transm 2013;120:1179-89.

78. Lima FAV, Joventino IP, Joventino FP, et al. Neuroprotective Activities of Spirulina platensis in the 6-OHDA Model of Parkinson's Disease Are Related to Its Anti-Inflammatory Effects. Neurochem Res 2017;42:3390-400.

79. Marcel A-K, Ekali LG, Eugene S, et al. The effect of Spirulina platensis versus soybean on insulin resistance in HIV-infected patients: a randomized pilot study. Nutrients 2011;3:712-24.

80. Dekker D, Dorresteijn MJ, Pijnenburg M, et al. The bilirubinincreasing drug atazanavir improves endothelial function in patients with type 2 diabetes mellitus. Arterioscler Thromb Vasc Bio 2011;31:458-63.

81. Wang X, Ge A, Cheng M, et al. Increased hypothalamic inflammation associated with the susceptibility to obesity in rats exposed to high-fat diet. Exp Diabetes Res 2012;2012:1-8.

82. Seo Y-J, Kim K-J, Choi J, et al. Spirulina maxima extract reduces obesity through suppression of adipogenesis and activation of browning in 3T3-L1 cells and high-fat diet-induced obese mice. Nutrients 2018;10.

83. Heo M-G, Choung S-Y. Anti-obesity effects of Spirulina maxima in high fat diet induced obese rats via the activation of AMPK pathway and SIRT1. Food Funct 2018:9:4906-15.

84. Yousefi R, Mottaghi A, Saidpour A. Spirulina platensis effectively ameliorates anthropometric measurements and obesityrelated metabolic disorders in obese or overweight healthy individuals: a randomized controlled trial. Complement Ther Med 2018;40:106-12.

85. Aragonès $\mathrm{G}$, Ardid-Ruiz $\mathrm{A}$, Ibars $\mathrm{M}$, et al. Modulation of leptin resistance by food compounds. Mol Nutr Food Res 2016;60:1789-803.

86. Yoshimatsu H, Itateyama E, Kondou S, et al. Hypothalamic neuronal histamine as a target of leptin in feeding behavior. Diabetes 1999;48:2286-91.

87. Yoshimatsu $\mathrm{H}$. Hypothalamic neuronal histamine regulates body weight through the modulation of diurnal feeding rhythm. Nutrition 2008;24:827-31.

88. Kasaoka S, Tsuboyama-Kasaoka N, Kawahara Y, et al. Histidine supplementation suppresses food intake and fat accumulation in rats. Nutrition 2004;20:991-6.

89. Yoshimatsu H, Chiba S, Tajima D, et al. Histidine suppresses food intake through its conversion into neuronal histamine. Exp Biol Med 2002;227:63-8.

90. Yoshimatsu H, Tsuda K, Niijima A, et al. Histidine induces lipolysis through sympathetic nerve in white adipose tissue. Eur J Clin Invest 2002;32:236-41.

91. Yasuda T, Masaki T, Chiba S, et al. L-histidine stimulates sympathetic nerve activity to brown adipose tissue in rats. Neurosci Lett 2004;362:71-4.

92. Sun X, Feng R, Li Y, et al. Histidine supplementation alleviates inflammation in the adipose tissue of high-fat diet-induced obese

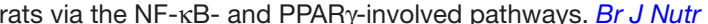
2014; $112: 477-85$

93. Feng RN, Niu YC, Sun XW, et al. Histidine supplementation improves insulin resistance through suppressed inflammation in obese women with the metabolic syndrome: a randomised controlled trial. Diabetologia 2013;56:985-94.

94. YC L, CL L, JY Q, et al. Relationships of dietary histidine and obesity in northern Chinese adults, an Internet-based crosssectional study. Nutrients 2016;8.

95. Okubo H, Sasaki S. Histidine intake may negatively correlate with energy intake in human: a cross-sectional study in Japanese female students aged 18 years. J Nutr Sci Vitaminol 2005;51:329-34.

96. Jørgensen EA, Vogelsang TW, Knigge U, et al. Increased susceptibility to diet-induced obesity in histamine-deficient mice. Neuroendocrinology 2006;83:289-94.

97. DiNicolantonio JJ, McCarty MF, OKeefe JH. Role of dietary histidine in the prevention of obesity and metabolic syndrome. Open Heart. In Press 2018;5

98. IC Y, Lin HY, Liu NC, et al. Neuronal androgen receptor regulates insulin sensitivity via suppression of hypothalamic NF-kappaBmediated PTP1B expression. Diabetes 2013;62:411-23.

99. Kintzel PE, Chase SL, Schultz LM, et al. Increased risk of metabolic syndrome, diabetes mellitus, and cardiovascular disease in men receiving androgen deprivation therapy for prostate cancer. Pharmacotherapy 2008;28:1511-22.

100. Collier A, Ghosh S, McGlynn B, et al. Prostate cancer, androgen deprivation therapy, obesity, the metabolic syndrome, type 2 diabetes, and cardiovascular disease. Am J Clin Oncol 2012;35:504-9.

101. Traish AM, Guay A, Feeley R, et al. The dark side of testosterone deficiency: I. Metabolic syndrome and erectile dysfunction. J Androl 2009;30:10-22.

102. Haring $\mathrm{R}$, Völzke $\mathrm{H}$, Felix SB, et al. Prediction of metabolic syndrome by low serum testosterone levels in men: results from the study of health in Pomerania. Diabetes 2009;58:2027-31.

103. Saad F, Aversa A, Isidori AM, et al. Testosterone as potential effective therapy in treatment of obesity in men with testosterone deficiency: a review. Curr Diabetes Rev 2012;8:131-43.

104. Zhang Z-Y, Lee S-Y. PTP1B inhibitors as potential therapeutics in the treatment of type 2 diabetes and obesity. Expert Opin Investig Drugs 2003;12:223-33. 
105. Krishnan N, Konidaris KF, Gasser G, et al. A potent, selective, and orally bioavailable inhibitor of the protein-tyrosine phosphatase PTP1B improves insulin and leptin signaling in animal models. $J$ Biol Chem 2018:293:1517-25.

106. Imparl-Radosevich J, Deas S, Polansky MM, et al. Regulation of PTP-1 and insulin receptor kinase by fractions from cinnamon: implications for cinnamon regulation of insulin signalling. Horm Res 1998;50:177-82.
107. Couturier K, Batandier C, Awada M, et al. Cinnamon improves insulin sensitivity and alters the body composition in an animal model of the metabolic syndrome. Arch Biochem Biophys 2010;501:158-61.

108. Borzoei A, Rafraf M, Asghari-Jafarabadi M. Cinnamon improves metabolic factors without detectable effects on adiponectin in women with polycystic ovary syndrome. Asia Pac J Clin Nutr 2018;27:556-63. 